Không có bệnh nhân nào có những tai biến lớn (võ ổ áp xe, chảy máu đường mật) do đặt sonde gây ra. Chỉ có 1 bệnh nhân bị tắc sonde dẫn lưu.

\section{BÀN LUẬN}

Nhóm bệnh nhân trong nghiên cứu của chúng tôi có độ tuổi trung bình là $53,1 \pm 15,7$ tuổi. Tuổi trung bình trong nhóm bệnh nhân của chúng tôi cao hơn của tác giả Malik [4]. Trong nhóm nghiên cứu của chúng tôi tỷ lệ nam giới gặp nhiều hơn nữ giới với tỷ lệ nam giới là $63,9 \%$. Tỷ lệ nam/ nữ là 1,77 . Trong số 36 bệnh nhân nghiên cứu, tất cả đều được lấy mủ gửi vi sinh cây định danh vi khuẩn bằng máy tự động. Kết quả có 20 bệnh nhân âm tính và 16 bệnh nhân dương tính với những loại vi khuẩn khác nhau. Trong nhóm bệnh nhân cấy mủ âm tính thì có 2 bệnh nhân có cả xét nghiệm Elisa a míp và Elisa sán lá gan lớn đều âm tính. Do đó, trong nghiên cứu của chúng tôi có thể xem là bao gồm 18 bệnh nhân áp xe gan vi khuẩn (16 cấy mủ dương tính và 2 cây mủ âm tính) chiếm $50 \%$ bệnh nhân, và 18 bệnh nhân là áp xe gan không được xác định rõ chiếm $50 \%$. Kích thước ổ áp xe trung bình trong nghiên cứu của chúng tôi là $8,54 \pm 2,12 \mathrm{~cm}$, tất cả 36 bệnh nhân đều có kích thước ố áp xe lớn hơn $5 \mathrm{~cm}$ với kích thước nhỏ nhất của ổ áp xe là $5,2 \mathrm{~cm}$ và kích thước lớn nhất là $14,8 \mathrm{~cm}$, trong đó 27 bệnh nhân có đường kính ổ áp xe trong khoảng từ $5-10 \mathrm{~cm}$ chiếm 75\% số bệnh nhân, 9 bệnh nhân có ổ áp xe kích thước trền $10 \mathrm{~cm}$ phù hợp để dẫn lưu qua sonde pigtail so với các tác giả nước ngoài [1, 5]. Số thủ thuật được thực hiện trong nghiên cứu là 37 lượt, với tỷ lệ thành công của thủ thuật là $100 \%$. Tỷ lệ này cao như vậy là do thủ thuật được thực hiện dưới sự hướng dẫn của siêu âm và bác sỹ làm thủ thuật có trình độ cao.
35 bệnh nhân còn lại mỗi bệnh nhân được đặt 1 sonde Pigtail dẫn lưu với 1 lần thực hiện, còn lại 1 bênh nhân được đăt sonde 2 lần. Bệnh nhân này chỉ có 1 ổ áp xe, lúc đầu tiên được đặt dẫn lưu bằng sonde Pigtail cõ $8 \mathrm{~F}$ nhưng do mủ áp xe đặc, kích thước lớn, ổ áp xe có nhiều khí nên phải thay bằng sonde dẫn lưu có kích thước lớn hơn (12 F), một số bệnh nhân phải đặt nhiêu lần giống như một số tác giả khác trên thế giới $[3,4,6]$.

Sau khi điều trị thì tất cả các chỉ số viêm đều có sự cải thiện hơn so với trước khi điều trị, tất cả bệnh nhân đều hết sốt, nó khẳng định hiệu quả của phương pháp điều trị này.

\section{KẾT LUÂN}

Qua nghiên cứu 36 bệnh nhân áp xe gan lớn trên 5 được điều trị bằng nọi khoa kết hợp với đặt sonde Pigtail chúng tôi nhận thấy rằng đây là phương pháp là hiệu quả và an toàn.

\section{TÀI LIÊU THAM KHẢO}

1. Ruiz-Hernández, J.J., et al., Pyogenic liver abscesses: mortality-related factors. Eur J Gastroenterol Hepatol, 2007. 19(10): p. 853-8.

2. Blessmann, J., et al., Epidemiology of amebiasis in a region of high incidence of amebic liver abscess in central Vietnam. Am J Trop Med Hyg, 2002. 66(5): p. 578-83.

3. Cai, Y.L., et al., Percutaneous needle aspiration versus catheter drainage in the management of liver abscess: a systematic review and metaanalysis. HPB (Oxford), 2015. 17(3): p. 195-201.

4. Malik, A.A., et al., Pyogenic liver abscess: Changing patterns in approach. World J Gastrointest Surg, 2010. 2(12): p. 395-401.

5. Mischinger, H.J., et al., Pyogenic liver abscess: studies of therapy and analysis of risk factors. World J Surg, 1994. 18(6): p. 852-7; discussion 858.

6. Qian, $Y_{.,}$et al., A retrospective study of pyogenic liver abscess focusing on Klebsiella pneumoniae as a primary pathogen in China from 1994 to 2015. Sci Rep, 2016. 6: p. 38587.

\title{
NGHIÊN CỨU NỒNG Độ IL-6 HUYẾT TƯƠNG, CHỈ SỐ HOMA2-IR TRÊN BÊ̂NH NHÂN ĐÁI THÁO ĐƯỜNG TYP2
}

\section{TÓM TẮT}

\author{
*Bênh viên Bach Mai \\ Chịu trách nhiệm chính: Nguyễn Thị Duyên \\ Email: duyen90108@gmail.com \\ Ngày nhận bài: 26.7.2021 \\ Ngày phản biên khoa hoc: 20.9.2021 \\ Ngày duyệt bài: 29.9.2021
}

\section{Nguyễn Thị Duyên*, Bùi Tuấn Anh*}

Đái tháo đường typ2 (ĐTĐ typ2) hiện đang là một vấn đề lớn của sức khỏe toàn câu. Bềnh có cơ chế bệnh sinh phức tạp trong đó có tình trạng đề kháng insulin. Chỉ số HOMA2-IR là một chỉ số đánh giá tình trạng kháng insulin một cách khách quan, ít can thiệp. Interleukin-6 là môt cytokine có mối liên quan đển tình trạng béo phì, kháng Insulin ở bệnh nhân ĐTĐ typ2. Trong nghiên cứu này chúng tôi tính toán chỉ số HOMA2-IR và định lượng IL-6 ở bệnh nhân ĐTĐ type2 
so sánh với nhóm chứng và xét mối tương quan giữa hai chỉ số . Kết quả: Chỉ số HOMA2-IR ở nhóm bệnh là: $2.92 \pm 1.75$ và nhóm chứng là: $1.52 \pm 0.68$; nồng độ IL-6 huyết tương ở nhóm bệnh là $3.15 \pm 2.19 \mathrm{pg} / \mathrm{mL}$ và̀ nhóm chứng là: $1.85 \pm 0,91 \mathrm{pg} / \mathrm{mL}$ với $\mathrm{p}<0.05$. Có mối tương quan thuận chặt giữa nông độ IL-6 huyết tương và chỉ số HOMẢ2-IR với $r=0.5, p<0.01$. Kết luận: Có sự khác biệt giữa nồng độ IL-6 huyết tương và chỉ số HOMA2-IR của nhóm bênh và nhóm chứng.

Tư khóa: Đái tháo đường typ2 (ĐTĐ typ2), nồng độ IL-6 huyết tương, chỉ số HOMA2-IR

\section{SUMMARY \\ PLASMA IL-6 LEVEL AND HOMA2-IR INDEX IN TYPE 2 DIABETES PAINTIENTS}

Type 2 diabetes mellitus (T2DM) has been one ot the most concerned health problem globally. T2DM has a complex pathogenesis including insulin resistance. HOMA2-IR is a tool used for objective and non-invasive assessment of insulin resistance. Interleukin-6 is a cytokine related to obesity and insulin resistance in T2DM patients. In this study, we calculated HOMA2-IR index and measured IL-6 level of T2DM patients to compare with healthy control group and analyze the relation. Result: HOMA2-IR index in disease group was $2.92 \pm 1.75$ and that of healthy control group was $1.52 \pm 0.68$; while plasma IL-6 level in disease group was $3.15 \pm 2.19 \mathrm{pg} / \mathrm{ml}$ and control group was $1.85 \pm 0,91 \mathrm{pg} / \mathrm{mL}$ with $\mathrm{p}<0.05$. There was a proportional moderate relation betwwen plasma IL6 level and HOMA2-IR index with $r=0.569, p<0.01$. Conclusion: There was a statistically significane in the difference between HOMA2-IR index and plasma IL-6 level of disease group and control group.

Keywords: Type 2 diabetes mellitus (T2DM), plasma IL-6 level, HOMA2-IR index

\section{I. ĐĂT VẤN ĐỀ}

Bệnh ĐTĐ typ 2 chiếm đa số các trường hợp bị ĐTंĐ. Cơ chế bệnh sinh của ĐTĐ typ 2 rất phức tạp nhưng chủ yếu là kháng insulin và rối loạn bài tiết insulin. Kháng insulin là tình trạng suy giảm đáp ứng sinh học đối với insulin, biểu hiện thông thường bằng sự gia tăng nồng độ insulin trong máu. Nhiều nghiên cứu đã chứng minh tình trạng kháng insulin thường đi trước sự xuất hiện của các triệu chứng lâm sàng của bệnh ĐTĐ typ 2. Khi nồng độ insulin không đủ để vượt qua tình trạng đề kháng gây tăng glucose máu mạn tính và bệnh ĐTÐ thực sự sẽ xuất hiện ${ }^{1,2}$. Việc đánh giá tình trạng kháng Insulin mang lại nhiều giá trị cho việc tiên lượng bệnh và điều trị bệnh ĐTÐ typ2. Trên thế giới hiên có nhiều phương pháp, chỉ số để thăm dò̀ tình trạng kháng Insulin như: kỹ thuật kẹp glucose, định lượng Insulin lúc đói, chỉ số Benedict, QUICKI, HOMA2-IR 5... trong đó chỉ số HOMA2-IR là một chỉ số đánh giá tình trạng kháng Insulin một cách khách quan, ít can thiệp được Matthews DR đề xuất năm 1985 và sau đó được Tổ chức $y$ tế Thế giới (WHO) công nhận cách xác định này để đánh giá kháng Insulin.

Sự hiện diện của các yếu tố viêm với nồng độ thấp là một yếu tố quan trọng trong sự phát triển và tiến triển của các bệnh lý như đái tháo đường týp 2 và bệnh lý tim mạch ${ }^{3}$. Interleukin- 6 là một cytokines viêm có nhiều tác dụng sinh học khác nhau, có nhiều nghiên cứu đã chỉ ra rằng IL-6 có mối liên quan đến tình trạng béo phì, kháng Insulin và bệnh ĐTĐ typ2 $2^{3,4}$. Cho đến nay ở Việt Nam vẫn chưa có nhiêu nghiên cứu nào về mối tương quan giữa IL-6 với HOMA2-IR trên bệnh nhân ĐTĐ typ2. Xuất phát từ thực tế trên, chúng tôi tiến hành đề tài: "Nghiên cứu nồng độ IL-6 huyết tương, chỉ số HOMA2-IR trên bệnh nhân đái tháo đường typ2" với 2 mục tiêu:

1. Khảo sát nồng độ IL-6 huyêt tương, chỉ số HOMA2-IR trên bệnh nhân đái tháo đường typ2 tại khoa khám bệnh bênh viện Bạch Mai.

2. Tìm hiểu mối liên quan giữa nồng độ IL-6 huyêt tương với chi số HOMA2-IR và một số thông số hóa sinh ở đối tượng nghiên cứu trên.

II. ĐỐl TƯợNG VÀ PHƯƠNG PHÁP NGHIÊN CỨU

1. Đối tượng nghiên cứu. Tất cả bệnh nhân được khám và điểu trị tại bệnh viện Bạch Mai.

Thời gian: từ tháng 3 năm 2020 đến tháng 10 năm 2021

Địa điểm: khoa Khám bệnh và Hóa sinh bệnh viện Bạch Mai.

\section{Phương pháp nghiên cứu}

- Thiết kế: nghiên cứu mô tả cắt ngang

- Mẫu nghiên cứu:

+ Áp dụng công thức tính cõ̃ mẫu cho nghiên cứu với hai nhóm đối tượng để so sánh hai chỉ số trung bình

+ Tiêu chuẩn lưa chọn bệnh nhân: bệnh nhân được chẩn đoán ĐTĐ typ2 HbA1c $\geq 6,5 \%$ hoặc đường máu bất kỳ $\geq 11,1 \mathrm{mmol} / \mathrm{l}$ có kèm các triệu chứng lâm sàng hoặc đường máu lúc đói $\geq 7 \mathrm{mmol} / \mathrm{l}$, hoặc bệnh nhân đã nhịn đói ít nhất 8h (8-14h), xét nghiệm ít nhất 02 lần, hoặc đường máu $2 \mathrm{~h}$ sau làm nghiệm pháp tăng glucose máu $\geq 11,1 \mathrm{mmol} /$; k không điều trị Insulin; bệnh nhân đồng ý tham gia nghiên cứu.

+ Tiêu chuấn loại trừ: ĐTÐ typ1, ĐTÐ thai nghén hoặc các đái tháo đường khác thứ phát sau dùng thuốc, do basedow, hội chứng Cushing... Tất cả các trường hợp nhiễm trùng cấp tính và mạn tính, các bệnh lý hệ cơ xương khớp và bệnh lý hệ thống, chấn thương, bệnh nhân có thai và cho con bú, bệnh nhân mắc chứng bệnh trầm cảm, bệnh nhân không đồng ý tham gia nghiên cứu. 
- Chi tiêu nghiên cứu:

+ Chỉ tiêu chung: Tuổi, giới, BMI

+ Chỉ tiêu cận lâm sàng: một số chỉ số sinh hóa máu

- Thu thập số liệu: Mẫu máu được lấy ống sinh hóa chống đông bằng heparin được ly tâm ở tốc độ 3500 vòng / phút trong 10 phút, và các mẫu huyết tương được bảo quản ở $-80^{\circ} \mathrm{C}$ cho đến ngày phân tích. Xét nghiệm IL-6 được đo bằng phương pháp miễn dịch điện hóa phát quang trên máy cobas e602 tại khoa Hóa sinh bênh viên Bach Mai.

Xử lý số liệu: Phần mềm SPSS 20.0

\section{KẾT QUẢ NGHIÊN CỨU}

3.1. Đặc điểm của đối tượng nghiên cứu

Bảng 3.1: Đặc điểm tuối và giới giứa nhóm ĐTÐ typ2 và nhóm chứng

\begin{tabular}{|c|c|c|c|c|}
\hline \multicolumn{2}{|c|}{} & \multicolumn{2}{c|}{ Nhóm } & \multirow{2}{*}{ P } \\
\cline { 3 - 5 } & Bệnh & Chứng & \\
\hline \multirow{2}{*}{ Giới } & Nam (\%) & 54.3 & 51.4 & \multirow{2}{*}{$>0.05$} \\
\cline { 2 - 4 } & Nữ (\%) & 45.7 & 48.6 & \\
\hline \multirow{2}{*}{ Tuổi } & Trung bình & $\begin{array}{c}52.74 \pm \\
11.51\end{array}$ & $\begin{array}{c}50.06 \pm \\
11.5\end{array}$ & $>0.05$ \\
\hline BMI & Trung bình & 18.4 & 17.48 & $<0.01$ \\
\hline
\end{tabular}

Nhân xét: -Không có sự khác biêt về tuối và giới giữa nhóm ĐTÐ typ2 và nhóm chứng.

- BMI trung bình của nhóm bênh cao hơn nhóm chứng có ý nghĩa thống kê với $p<0.01$.

\subsection{Nông độ IL-6 huyết tương và chỉ số HOMA2-IR của đối tượng nghiên cứu}

3.2.1. Nồng độ IL-6 huyêt tương và chỉ số HOMA2-IR trung bình ở nhóm ĐTĐ typ2 và nhóm chứng

\begin{tabular}{|c|c|c|c|c|c|c|c|c|}
\hline \multirow{2}{*}{ Đối tượng } & \multicolumn{4}{|c|}{ IL-6 (pg/mL) } & \multicolumn{4}{|c|}{ HOMA2-IR } \\
\hline & Min & Max & $X \pm S D$ & $\mathbf{p}$ & Min & Max & $X \pm S D$ & $\mathbf{p}$ \\
\hline Nhól & 1.5 & 11.77 & $3.15 \pm 2.19$ & $<0.05$ & 0.70 & 11.20 & $2.92 \pm 1.75$ & $<0.05$ \\
\hline Nhóm chứng $(n=70)$ & 1.5 & 5.62 & $1.85 \pm 0.91$ & & 0.62 & 4.05 & $1.52 \pm 0.68$ & \\
\hline
\end{tabular}

Nhân xét: Nồng đô IL-6 và chỉ số HOAM2-IR ở nhóm ĐTĐ typ2 cao hơn nhóm chứng sự khác biệt có ý nghĩa thống kể với $\mathrm{p}<0.05$.

2.2.2. Nồng đố IL-6 huyêt thanh và chỉ số HOMA2-IR trung binh theo BMI ở nhóm bệnh và nhóm chứng

\begin{tabular}{|c|c|c|c|c|c|}
\hline Đôi tượng & BMI & $\begin{array}{c}\text { IL-6; } \bar{X} \pm \text { SD } \\
(\mathrm{pq} / \mathrm{mL})\end{array}$ & $\mathbf{p}$ & $\begin{array}{c}\text { HOMA2-IR; } \bar{X} \pm \text { SD } \\
(\mathrm{pq} / \mathrm{mL}\end{array}$ & $\mathbf{p}$ \\
\hline \multirow{2}{*}{$\begin{array}{l}\text { Nhóm bênh } \\
(n=70)\end{array}$} & $<23(n=23)$ & $2.49 \pm 1.34$ & \multirow{4}{*}{$<0.05$} & $2.13 \pm 1.15$ & \multirow{4}{*}{$<0.05$} \\
\hline & $\geq 23(n=47)$ & $3.47 \pm 2.46$ & & $3.30 \pm 1.87$ & \\
\hline \multirow{2}{*}{$\begin{array}{l}\text { Nhóm chứng } \\
(\mathrm{n}=70)\end{array}$} & $<23(n=46)$ & $1.60 \pm 0,48$ & & $1.33 \pm 0,49$ & \\
\hline & $\geq 23(n=24)$ & $2.33 \pm 1.30$ & & $1.89 \pm 0.84$ & \\
\hline
\end{tabular}

Nhân xét: nồng độ IL-6 huyết tương và chỉ số HOMA2-IR ở các đối tượng nghiên cứu có BMI $\geq 23$ cao hơn nhóm có BMI<23.

3.2.3. Tương quan giữa nồng độ $I L-6$ với chỉ số HOMA2-IR và một số thông số

\begin{tabular}{|c|c|c|}
\hline \multirow{2}{*}{ Thông số XN } & \multicolumn{2}{|c|}{ Nhóm bệnh } \\
\cline { 2 - 3 } & $\mathbf{R}$ & $\mathbf{P}$ \\
\hline BMI & $\mathbf{0 . 3 6 9}$ & $<\mathbf{0 . 0 5}$ \\
\hline HOMA2-IR & $\mathbf{0 . 5 6 9}$ & $<\mathbf{0 . 0 1}$ \\
\hline CRPhs & 0.134 & $>0.05$ \\
\hline Cholesterol & -0.04 & $>0.05$ \\
\hline Triglycerid & 0.224 & $>0.05$ \\
\hline HDL-C & -0.109 & $>0.05$ \\
\hline LDL-C & -0.79 & $>0.05$ \\
\hline Glucose & $\mathbf{0 . 4 1}$ & $<\mathbf{0 . 0 5}$ \\
\hline HbA1c & $\mathbf{0 . 3 8}$ & $<\mathbf{0 . 0 5}$ \\
\hline
\end{tabular}

Nhân xét: Nồng độ IL-6 huyết tương tương quan thuận với chỉ số BMI, HOMA2-IR, nồng độ Glucose máu lúc đói và $\mathrm{HbA} 1 \mathrm{c}$.

\section{BÀN LUẬN}

4.1. Đặc điểm chung của đối tượng nghiên cứu. Nghiên cứu của chúng tôi tuyển

chon 70 bênh nhân mắc ĐTĐ typ2 đến khám và điều trị tại khoa Khám bệnh bệnh viện Bạch Mai và 70 bệnh nhân khỏe mạnh làm nhóm chứng. Không có sự khác biệt có ý nghĩa thống kê về tuổi và giới giữa các nhóm đối tượng nghiên cứu. Chỉ số BMI ở nhóm bệnh cao hơn có ý nghĩ thống kê so với nhóm chứng với $p<0.01$.

2.3. Nồng độ IL-6 huyết tương, chỉ số HOM2-IR ở bệnh nhân ĐTĐ typ2. Nghiên cứu của chúng tôi thu được kết quả trung bình của nồng độ IL-6 huyết tương của 70 bệnh nhân ĐTÐ typ 2 là $2.74 \pm 2.13(\mathrm{pg} / \mathrm{mL})$, cao hơn có ý nghĩa thống kê $(p<0,05)$ so với giá trị trung bình nồng độ IL-6 huyết tương của nhóm chứng là $1.85 \pm 0.91(\mathrm{pg} / \mathrm{mL})$, kết quả của chúng tôi tương đồng với nghiên cứu của Marques Vihdal cùng cộng sự (2013) ${ }^{5}$ cũng ghi nhận nồng độ IL6 huyết thanh của nhóm ĐTĐ typ2 cao hơn có ý nghĩa thống kê so với nhóm chứng $(p<0,001)$.

Nghiên cứu của chúng tôi thu được kết quả 
trung bình của chỉ số HOMA2-IR của nhóm ĐTÐ typ 2 là $2.92 \pm 1.75$ (Bảng 3.7) cao hơn nhóm chứng có ý nghĩa thống kê với $p<0.05$ và cao hơn tứ phân vị trên của nhóm chứng là 1.78

Nồng độ IL-6 huyết tương và chỉ số HOMA2IR ở nhóm có chỉ số $B M I \geq 23$ cao hơn nhóm còn lại, sự khác biệt có ý nghĩa thống kê với $p<0.05$. Kết quả trên tương đồng với kết quả trong nghiên cứu của Rajeev Goyal và cộng sự

Trong nghiên cứu của chúng tôi cũng khảo sát mối liên quan giữa nồng độ IL-6 huyết tương với chỉ số HOMA2-IR và một số chỉ số hoa sinh cơ bản. Kết quả nghiên cứu cho thấy mối tương quan thuận, mức độ tương quan chặt giữa nồng độ IL-6 huyết tương với chỉ số HOMA2-IR điều này phù hợp với kết quả nghiên cứu của Kern và cộng sự năm $2001^{7}$. Ngoài ra kết quả nghiên cứu cững thể hiện mối tương quan thuận giữa nồng độ IL-6 huyết tương với các chỉ số BMI, HbA1c và nồng độ Glucose máu lúc đói.

\section{KẾT LUẬN}

Khi khảo sát nồng độ IL-6 huyết tương và chỉ số HOMA2-IR trên bệnh nhân ĐTĐ typ2 tại Bệnh viện Bạch Mai từ tháng 3/2020 đên tháng 10/2021, chúng tôi đưa ra một số kết luận sau:

Có sự khác biệt giữa nồng độ IL-6 huyết tương và chỉ số HOMA2-IR giữa nhóm bệnh và nhóm chứng, giữa nhóm béo phì và không béo phì.

Có mối tương quan thuận, mức độ tương đối chặt giữa nồng độ IL-6 huyết tương với chỉ số
HOMA2-IR và nồng độ Glucose máu lúc đói, $\mathrm{HbA1C.}$

\section{TÀI LIÊU THAM KHẢO}

1. Freeman AM, Pennings N. Insulin Resistance. In: StatPearls. StatPearls Publishing; 2021. Accessed July 31, 2021. http://www.ncbi.nlm.nih.gov/books/NBK507839/

2. Inchiostro $\mathbf{S}$. Measurement of insulin sensitivity in Type 2 diabetes mellitus: comparison between KITT and HOMA-\% $S$ indices and evaluation of their relationship with the components of the insulin resistance syndrome. Diabetic medicine. 2005;22(1):39-44.

3. Lehrskov LL, Christensen RH. The role of interleukin-6 in glucose homeostasis and lipid metabolism. Semin Immunopathol. 2019;41(4): 491-499. doi:10.1007/s00281-019-00747-2

4. Akbari M, Hassan-Zadeh V. IL-6 signalling pathways and the development of type 2 diabetes. Inflammopharmacology. 2018;26(3):685-698. doi:10.1007/s10787-018-0458-0

5. Marques-Vidal $\mathbf{P}$, Bastardot $F$, von Känel $\mathbf{R}$, et al. Association between circulating cytokine levels, diabetes and insulin resistance in a population-based sample (CoLaus study). Clin Endocrinol (Oxf). 2013; 78(2):232-241. doi:10.1111/j.1365-2265.2012.04384.x

6. Goyal $R$, Faizy AF, Siddiqui SS, Singhai $M$. Evaluation of TNF-a and IL- 6 Levels in Obese and Non-obese Diabetics: Pre- and Postinsulin Effects. N Am J Med Sci. 2012;4(4):180-184. doi:10.4103/1947-2714.94944

7. Kern PA, Ranganathan S, Li C, Wood L, Ranganathan G. Adipose tissue tumor necrosis factor and interleukin-6 expression in human obesity and insulin resistance. Am J Physiol Endocrinol Metab. 2001;280(5):E745-751. doi:10.1152/ajpendo.2001.280.5.E745

\section{BÁO CÁO CA LÂM SÀNG PHẪU THUÂTT THÀNH CÔNG ĐIỀU TRI RÒ NộI MẠCH TYPE 1A SAU PHẪU THUÂ̂T VÒI VOI CẢI TIẾN}

\section{TÓM TẮT}

Rò nội mạch sau đặt ống ghép nội mạch là biến chứng điển hình, trong đó rò nội mạch type $1 \mathrm{~A}$ cần được theo dõi và xử lý sớm vì có nguy cơ gây võ túi phình. Trong giai đoạn đâu thực hiện kỹ thuật vòi voi cải tiến của Bệnh viện Hữu nghị Việt Đức chúng tôi không thực hiện khâu ép thành quai động mạch chủ sau thân cánh tay đâu vào vỏ của ống ghép, vì vậy có 2 ca xuất hiện rò nội mạch type $1 A$ sau mổ. Trong quá trình theo dõ̃i có 01 ca bệnh mức độ rò tăng lên và

*Bênh viện Hữu Nghi Việt Đức, Trường đại học Y Hà Nội Chịu trách nhiệm chính: Phạm Hữu Lư

Email: thachluu76@gmail.com

Ngày nhận bài: 2.8.2021

Ngày phản biện khoa học: 27.9.2021

Ngày duyệt bải: 4.10.2021

\section{Phùng Duy Hồng Sơn*, Phạm Hũu Lư*}

nguy cơ võ̃ cao, bệnh nhân này đã được phẫu thuật khâu lỗ rò và cho kết quả tốt. Chúng tôi thông báo ca bệnh này và hồi cứu y văn.

\section{SUMMARY}

\section{SURGICAL CLOSURE OF A TYPE 1A ENDOLEAK AFTER FROZEN ELEPHANT} TRUNK PROCEDURE: A CASE REPORT

Endoleaks are specific complications after thoracic aortic endovascular repair, in these endoleak type $1 \mathrm{~A}$ is serious and require carefully follow up and treatment, because high risk of aneurysm rupture. In the initial time, that became apply Viet Duc University Hospital modification of frozen elephant trunk technique, we did not fix the wall of aortic arch behind brachiocephalic trunk to graft and there were two cases with endoleak type $1 \mathrm{~A}$ after surgery. In one 